\title{
Optimization of electric discharge machining parameters on titanium alloy (ti-6al-4v) using Taguchi parametric design and genetic algorithm
}

\author{
K. Umanath ${ }^{1}$ and D.Devika ${ }^{2}$ \\ ${ }^{1}$ Assistant Professor, Department of Mechanical Engineering, Velammal Engineering college \\ ${ }^{2}$ Department of Mechanical Engineering, Saveetha School of Engineering, Saveetha Institute of Medical and Technical Sciences, \\ Chennai \\ Email id: umanathmech@gmail.com,ddevika40@gmail.com.
}

\begin{abstract}
The aim of this research work is to analyze the significant of process variables and find the optimum process variables in electric discharge machining (EDM) of Titanium alloy (Ti-6Al-4V). The variables considered are peak current, pulse-on-time and pulse-off-time where as the responses are Material Removal Rate(MRR) and Surface Roughness(SR). MITSUBISHI EA8 spark erosion machine is employed for this work and copper tungsten electrode of $\emptyset 14 \mathrm{~mm}$ is used in experimental trials. The experimental runs are done based on Taguchi L27 orthogonal array. The signal-to-noise ratio, the analysis of variance (ANOVA), regression analysis and Genetic algorithm are used to determine the optimal levels of machining parameters on Metal removal rate and Surface roughness. Confirmation tests also done with the optimal levels of machining variables. Comparison of Taguchi's and Genetic algorithm were employed to analyze the effective optimum value.
\end{abstract}

Keywords: EDM, Ti-6Al-4V alloy, Peak current, Pulse-on-time, Taguchi method.

\section{Introduction}

Ti-6Al-4V alloy is an essential material in modern industries. Its tremendous properties, such as high strength-weight ratio, high temperature resistance and outstanding corrosion resistance, make it extensively applied in the aerospace, automobile, chemical and biomedical fields. However, the poor machinability of titanium alloys using the conventional machining processes are more expensive. Therefore,non traditional machining ways, like discharge machining (EDM) are explored to machine this alloy. EDM is associate degree energy-based technique extensively utilized in machining hard, high-strength and temperature-resistant materials in an non contact manner. The alloy is melted and vaporized by an spark between the electrode and work piece.

Kao et al.used distilled water and kerosene as dielectric fluid .The higher material removal rate (MRR) and lower surface roughness (SR) obtained by distilled water.[1]. Ponappa et al. endeavored to upgrade the discharge efficiency of magnesium nano alumina composites utilizing by EDM [2]. Anand pandey et al. investigated the impact of EDM parameters at surface integrity with various electrodes and processes [3]. Recently, Velusamy et al. utilized EDM innovation to machine aluminum composites to inspect the impact of process parameters [4]. Sharma demonstrated the most effective parameters are pulse current and pulse duration at surface roughness of the workpiece when compare to other EDM parameters[5]. Yan-Cherng Lin et al demonstrated that the magnetic force helped EDM has a higher MRR, a lower relative electrode wear proportion and a littler Surface Roughness as contrasted with ordinary EDM [6]. Joshi and pande created insightful model for the electric discharge machining process utilizing two-dimensional axisymmetric thermal (FEM) model of single-spark EDM process and artificial neural network is utilized to predict the shape of creater cavity,MRR, and TWR [7]. Narender Singh and Raghukandan reported the multi-response optimization of the process parameters like MRR,TWR,Taper, radial overcut, and SR on electric discharge machining of $\mathrm{Al}-10 \% \mathrm{SiCP}$ as cast metal matrix composites utilizing orthogonal array with Grey relational analysis [8]. George et al considered EDM input parameters are pulse current, gap voltage and pulse-on-time and responses are electrode wear rate and material removal rate and obtained the optimized parameters on carbon carbon composite using taguchi method [9]. Elangovan et al and Akhyar et al used taguchi's robust design, analysis of variance and signal to noise ratio analyses to investigated the influence of different input parameters on the different 
output parameters [10,11]. Krishna Mohana Rao et al presented the optimized parameters of die sinking electric discharge machining on the surface roughness by considered the simultaneous affect of various input parameters using genetic algorithm [12]. Anand et al applied Grey Relational Analysis with Taguchi Technique to found the optimal selection of machining parameters such as peak current, pulse duration, voltage, Servo reference voltage in Electrical Discharge Machining process to identify the improvement in metal removal rate and surface finish of the work material $\mathrm{HCHCr}$ using copper electrode with assistance of magnetic field [13]. Chandramouli et al announced the optimal setting of the process parameters on Electric Discharge Machining, that have been chosen are peak current, pulse on time, pulse off time and tool lift time with output parameters as Material Removal Rate and Surface Roughness .Taguchi test configuration was utilized to plan the experimental run and investigations led on PH Steel machined with copper tungsten tool. [14]. In this work, the optimization of EDM process parameters on Ti-6Al-4Valloy using the Taguchi method and ANOVA analysis are reported. Output parameters including material removal rate and Surface Roughness are assessed the machining impacts. Those process parameters are firmly associated with the chosen regression analysis and output parameters in this investigation are the peak current, pulse-on-time and pulse-off-time. Experiments in view of L27 orthogonal array are led. Optimized process parameters all the while prompting higher material removal rate and better surface roughness is then be checked through an confirmation experiment. The points of interest of the methods are tended to in the accompanying areas.

\section{Experiments}

A cylindrical copper tungsten rod $14 \mathrm{~mm}$ in diameter and $100 \mathrm{~mm}$ in height was employed as the electrode in the CNC EDM machine (MITSUBISHI -EA8) to erode the work piece of Ti-6Al $4 \mathrm{~V}$ alloy in this work. The specimen size selected in this investigation is $25 \times 25 \times 5 \mathrm{~mm}$. The work piece properties of the alloy and the chemical compositions are shown in Table 1 . However, there are a few machining characteristics to be considered in the EDM process. As a result, a preliminary experiment for determining the optimal process parameters indicates the machining parameters such as peak current, pulse-on-time and pulse-off-time led a most significance on the Electric Discharge Machining performance of $\mathrm{Ti}-6 \mathrm{Al}-4 \mathrm{~V}$ alloy.
Table.1.Material properties of Ti-6Al-4V alloy and its chemical composition

\begin{tabular}{|l|c|}
\hline Work piece & Ti-6Al-4V \\
\hline Hardness $(\mathrm{HRC})$ & $36 \sim 39$ \\
\hline Solidus temperature $\left({ }^{\circ} \mathrm{C}\right)$ & $1,604 \pm 11$ \\
\hline Liquids temperature $\left({ }^{\circ} \mathrm{C}\right)$ & $1,660 \pm 14$ \\
\hline Density $\left(\mathrm{g} / \mathrm{cm}^{3}\right)$ & 4.043 \\
\hline Elastic modulus $\left(\mathrm{kg} / \mathrm{mm}^{2}\right)$ & 11,200 \\
\hline Yield strength $\left(\mathrm{kg} / \mathrm{mm}^{2}\right)$ & 84.2 \\
\hline Tensile strength $\left(\mathrm{kg} / \mathrm{mm}^{2}\right)$ & 91.3 \\
\hline Elongation $(\%)$ & 10 \\
\hline Electrical resistivity $(\mu \Omega \cdot \mathrm{m})$ & 1.7 \\
\hline
\end{tabular}

$\mathrm{Ti}=$ 89.464, $\mathrm{Al}=6.08, \quad \mathrm{~V}=4.02, \quad \mathrm{Fe}=0.22, \mathrm{O}=0.18$, $\mathrm{C}=\mathbf{0 . 0 2}, \quad \mathrm{N}=\mathbf{0 . 0 1}, \mathrm{H}=\mathbf{0 . 0 0 5 3}$

Table .2 .Machining parameter

\begin{tabular}{|l|l|l|l|l|}
\hline SL & Parameters & L1 & L2 & L3 \\
\hline A & Peak current, $(\mathrm{A})$ & 4.5 & 9.0 & 14 \\
\hline B & Pulse on time $(\mu \mathrm{s})$ & 6.0 & 12.8 & 25.6 \\
\hline C & Pulse off time $(\mu \mathrm{s})$ & 12.8 & 25.6 & 51.2 \\
\hline
\end{tabular}

Table .3.Fixed parameter

\begin{tabular}{|l|l|}
\hline Work piece & Ti-6Al-4V \\
\hline Electrode & Copper tungsten \\
\hline Dielectric fluid & DAPHANECUT-HL35 \\
\hline Polarity & Negative $(+)$ \\
\hline Machining depth & $0.2 \mathrm{~mm}$ \\
\hline
\end{tabular}

The selected Electric discharge machining parameters and its levels are listed in Table 2. In this experimental study electrode acted as positive polarity. DAPHANE CUT - HL35 dielectric fluid was employed in all experiments. The experimental setup is shown in the fig 1. The experiments are done based on L27 Taguchi orthogonal array. The fixed experimental parameters used in this work are listed in Table 3. This work also used MATLAB 7.4 to optimize the surface roughness and material removal rate using Genetic Algorithms. Each experiment was repeated two times and the average of values taken is for determining optimal parameters. The MRR and SR of the machined surface 
are the response variables to assess the machining quality. The MRR ( $\mathrm{mg} / \mathrm{min})$ is defined by volume of the material removed per unit time in minute. To measure the weight of the worn work piece removal, Sartorius Mechatronics (Model:BSA 224) was used. In the trials, the surface roughness of the EDMed work piece regarding the normally utilized $\mathrm{Ra}$ (arithmetic average roughness) was estimated by a surface roughness tester (Mitutoyo, Surftest-SJ201). Essentially, the MRR is the classification of higher-the-better responsible variable in the Taguchi technique and SR is the lower-the-better responsible variable in the Taguchi technique in the EDM process.

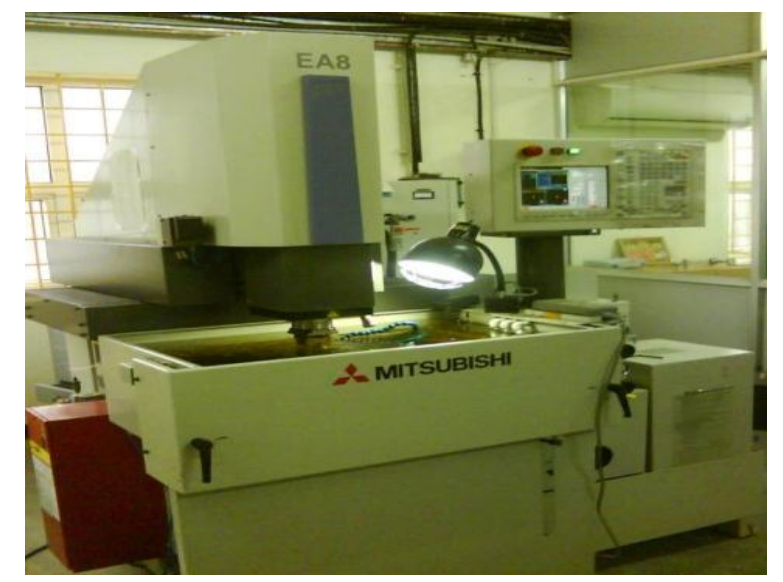

Figure.1. Experimental set up

\section{Taguchi's Method}

Taguchi's method is a well accepted methodology for experiment design. In this, signal-tonoise $\operatorname{ratio}(\mathrm{S} / \mathrm{N})$ is utilized to speak to a response variables and the largest $\mathrm{S} / \mathrm{N}$ ratio is required. There are three methods of quality characteristics viz. nominalthe-better, larger-the-better and smaller-the-better [15]. In this work, experimentally obtained MRR value is "larger the-better" and SR is "lower the-better". In view of Taguchi's technique, the $\mathrm{S} / \mathrm{N}$ ratio computed is as appeared in below.

i) Larger-the-better

$$
\text { HB : } \eta=-10 \log \left[\frac{1}{n} \sum_{i=1}^{n} y^{-2}\right]
$$

ii) Smaller-the-better

LB : $\eta=-10 \log \left[\frac{1}{n} \sum_{i=1}^{n} y i^{2}\right]$

Where $y i$ is the experimentally obtained value and $n$ is the repeated number of each experiment.

\section{Analysis of Variance (ANOVA)}

Analysis of Variance(ANOVA) is a numerical system which separates add up to variety into responsible sources. Some of the components in ANOVA are discussed below[15].

\subsection{Sum of squares}

The magnitude of each error value can be squared to provide a measurement of total variation present. This is known as "Sum of Squares". The basic ANOVA is that the total sum of squares is equal to the sum of sum of the squares due to known components as shown in Eq. 3.

$S S T=S S m+S S e$

Where,

SST - Total sum of squares.

SSm - sum of squares due to mean.

$\mathrm{SSe}$ - sum of squares due to error.

\subsection{Variance due to error}

Error Variance, for the most part named just variation, is equal to the sum of squares of error separated by the degree of freedom of errorError variance is a measure of the variation due to all the uncontrolled parameters, incorporating measurement error engaged with a specific experiment

\subsection{F -test for comparison}

The F-test is simply a ratio of sample variances as shown in Eq. 4.

$F=S y 1^{2} / S y 2^{2}$.

\subsection{Percent contribution}

The percent contribution indicates the relative power of a factor and/or interactions to reduce variation.

\section{Genetic Algorithm}

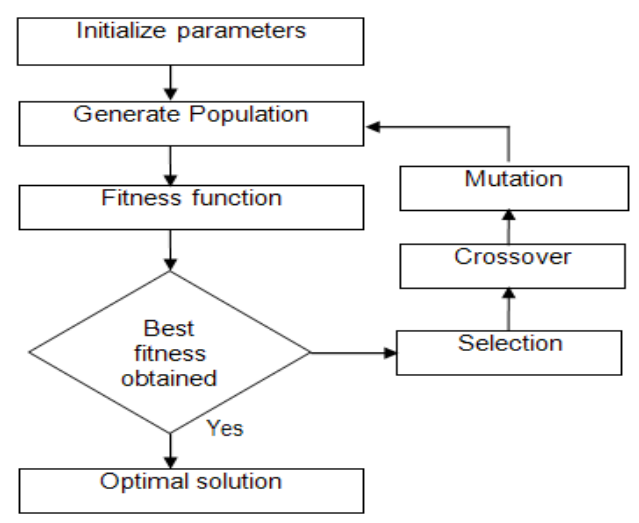

Figure.2. Flow of Optimization in GA

The aim of the optimization process using Genetic algorithm is to find the optimum values of decision variables that serve to the minimum value of surface roughness being as low as possible [12]. There will be a 
total of four optimization problems to be solved. Each optimization problem consists of a minimization function defined by one of the second order equations. Obtaining results in Genetic Algorithm (GA) is based on some criteria. as shown in fig 2 . The most essential parameters are population size, the type of selection function, the crossover rate and the mutation rate. By the process of experimentation the esteem or parameter setting for these criteria is made for acquiring the most optimum outcome that is normal from this investigation. The MATLAB optimization toolbox is applied in the study for performing iterations in order to get the best optimal outcome. The best mix of these qualities for cutting conditions will prompt the base lower surface roughness. Number of trials was directed with various esteem settings for the cutting conditions for looking through the minimization estimations of surface roughness utilizing the MATLAB optimization toolbox, the best blend of the parameters applied

\section{Results and Discussions}

\subsection{Regression analysis}

The peak current, pulse on time and pulse off time were considered in the development of regression equation for the material removal rate and surface roughness. A linear polynomial model is created to anticipate the material removal rate and surface roughness value for each experimental trail as recorded in Table.4.

The regression equation for material removal rate and surface roughness is shown in below

$$
\begin{aligned}
& M R R=-1.84+0.428 \text { Peak current }+0.0777 \text { Pulse on } \\
& \text { time }+0.0004 \text { Pulse off time.......... [5] } \\
& \begin{array}{l}
\text { SR }=3.25+0.0724 \text { Peak current }+0.0225 \text { Pulse on } \\
\text { time }-0.0215 \text { Pulse off time............... [6] }
\end{array}
\end{aligned}
$$

\subsection{Material removal rate}

Material removal rate is defined as the proportion of the difference of weight of the work piece before and after the machining to the machining time.

$M R R=(w j b-w j a) / t(\mathrm{mg} / \mathrm{min}) \ldots \ldots \ldots \ldots$ [7]

Where, wjb and wja are weights of work piece before and after the machining and $t$ is the machining time.

The machinability of EDM relies upon the electrical conductivity of the work material. Notwithstanding the low electrical conductivity and high thermal resistance of the material, which at last decreases the electrical conductivity of the work material, the outcomes acquired demonstrate that
Titanium alloy can be machined adequately utilizing EDM. MRR was found to increment with increment in current and pulse on time. It is likewise clear that the surface roughness value increments with increment in current and pulse on time. High current results in higher thermal loading on the two terminals (tool and work piece) trailed by higher amount of material being expelled from the two electrodes and thus prompt high MRR and as TWR as well. Furthermore, longer pulse duration also results in a large removal per discharge, which results in larger crater size and therefore higher surface roughness. The $\mathrm{S} / \mathrm{N}$ response graph in fig. 3 demonstrates the material removal rate increments with an increments in the current. For the performance characteristic of the material removal rate, the peak current level 3, pulse on time level 3 and pulse off time level 1 parameters including a current of 14A, pulse on time $25.6 \mu \mathrm{s}$ and pulse off time $12.8 \mu \mathrm{s}$ as shown in fig.3 can lead to optimal result. Optimum value is obtained from the response table. ANOVA results are shown in Table 5. Observation of this table discharge current is the most significant parameter having percentage of contribution as $62.74 \%$, followed by pulse on time $22.53 \%$ and pulse off time $5.18 \%$ are affect the material removal rate and the interaction factors are not contributing most significantly.

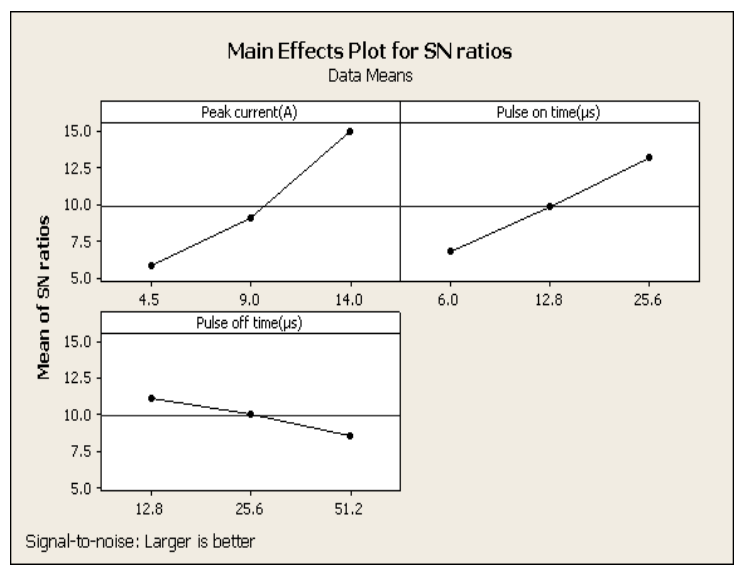

Figure 3. S/N ratio graph for MR

\subsection{Surface Roughness}

It was observed that pulse-off-time has a considerable effect on surface roughness. At the point when the pulse off time is incresed the machining also not done on the work piece that the time the dielectric fluid is applied into the spark gap, short-circuiting turns out to be less articulated because of the gathered particles. Higher pulse-off-time removes the formation of ionized bridges across the gap and results in higher ignition and decreased surface roughness. Further, the cooling rate of 
the tool increases with increase in the pulse off time and hence improved surface Roughness is observed.

It is found that the discharge current has a leading effect on surface roughness. The $\mathrm{S} / \mathrm{N}$ response graph in Fig. 4 shows the surface roughness decreases upon decreasing the discharge current. It indicates that a better surface quality can be obtained under a lower discharge current with shorter pulse duration owing to the lower power erosion process. Figure 4 shows when only the performance characteristic of the surface roughness is considered, a parameters set peak current level 1,pulse on time level 2 and pulse off time level 3 with a current of $4.5 \mathrm{~A}$, pulse on time $12.8 \mu \mathrm{s}$ and pulse off time $51.2 \mu$ s can result in an optimal outcome. Optimum values are getting from the response table. ANOVA table is shown in table 6 . From this table pulse off time is most significantly contribution is $20.78 \%$, peak current is $9.49 \%$,pulse on time is $8.69 \%$, interaction terms significantly contribution is $\mathrm{AB}, \mathrm{BC}$ and $\mathrm{AC}$ as $12.06 \%, 20.78 \%$ and $19.49 \%$ respectively. The electricdischarge machined surface consists of a huge number of craters that are formed by spark discharges. The electric-discharge machined surface comprises of a multitude of overlapping craters that are framed by spark discharges.

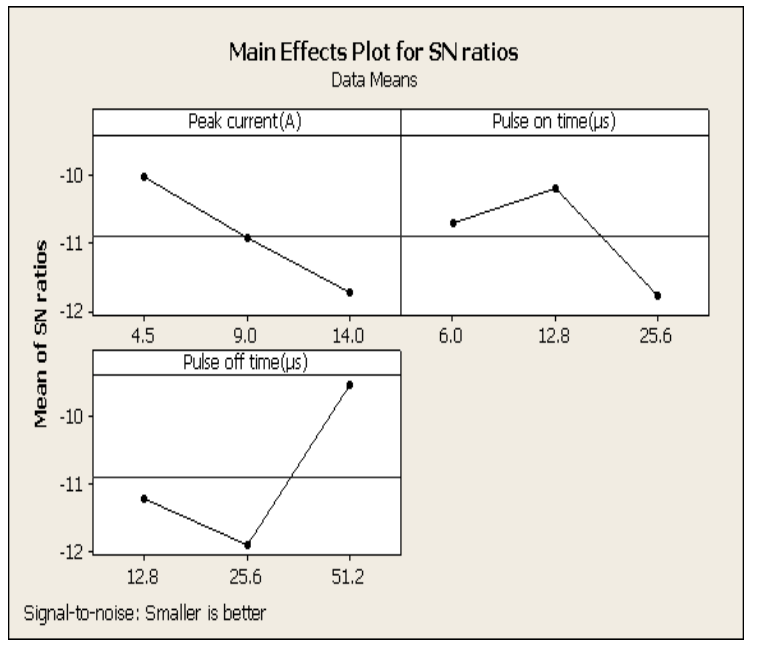

Fig 4. S/N ratio graph for SR

\subsection{Determination of surface roughness using GA}

The optimum choice of machining parameters should increment the utility of machining financial aspects, as well as the item quality, all things considered, by limiting surface roughness value. The process parameters of EDM are characterized in the standard optimization method that is solved by a numerical optimization algorithm. An objective function to be minimized is necessary to define the standard optimization problem. In EDM machining of titanium alloy, optimization problem can be expressed as

Minimize: a (IP,Ton,Toff)

Within range of machining parameters:

$$
\begin{aligned}
& 4.5 A<I P<14 A \\
& 6 \mu s<\text { Ton }<25.69 \mu \mathrm{s} \\
& 12.8 \mu \mathrm{s}<\text { Toff }<51.2 \mu \mathrm{s}
\end{aligned}
$$

The Genetic Algorithm based optimization approach gives an adequate estimate to the genuine optimum solution. Tables 7 and table 8 demonstrates the extraordinary of optimization work with important machining conditions.

$$
\begin{aligned}
& \text { Population size }=100 \\
& \text { Crossover rate }=0.95 \\
& \text { Mutation rate }=0.41
\end{aligned}
$$

MATLAB 7.4 is used to optimize the surface roughness using Genetic Algorithms. The critical parameters of the GA are the size of the population, cross over rate and mutation rate.

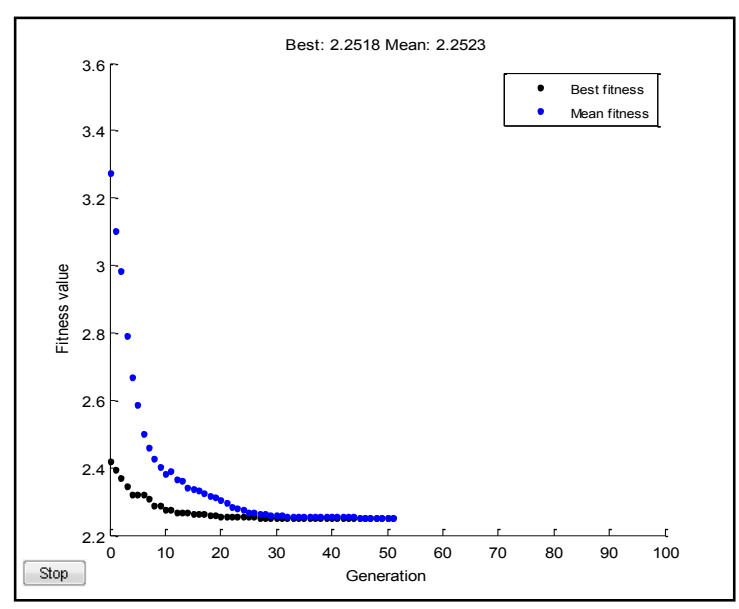

Figure 5. Genetic Algorithm fitness graph for SR 
Table 4. Experimental results for the MRR and SR

\begin{tabular}{|c|c|c|c|c|c|c|c|c|c|}
\hline Sl.No & $\begin{array}{l}\text { IP } \\
\text { (A) }\end{array}$ & $\begin{array}{l}\text { Ton } \\
(\mu s)\end{array}$ & Toff $(\mu s)$ & $\begin{array}{l}\text { Avg.SR( } \\
\mu \mathrm{m})\end{array}$ & $\begin{array}{l}\text { Predicted } \\
\text { SR }(\mu \mathrm{m})\end{array}$ & $\begin{array}{l}S / N \text { ratio } \\
\text { for } S R\end{array}$ & $\begin{array}{l}\text { Avg.MRR } \\
\text { (mg/min) }\end{array}$ & $\begin{array}{l}\text { Predicted } \\
\text { MRR }\end{array}$ & $\begin{array}{ll}\text { S/N for } \\
\text { MRR }\end{array}$ \\
\hline 1 & 4.5 & 6.0 & 12.8 & 2.73 & 3.2470 & -8.7233 & 1.013 & 1.3377 & 0.1122 \\
\hline 2 & 4.5 & 6.0 & 25.6 & 3.21 & 3.1604 & -10.1301 & 1.121 & 0.9844 & 0.9921 \\
\hline 3 & 4.5 & 6.0 & 51.2 & 2.32 & 2.6100 & -7.3098 & 1.596 & 1.1190 & 4.0607 \\
\hline 4 & 4.5 & 12.8 & 12.8 & 3.42 & 3.5886 & -10.6805 & 2.345 & 2.1060 & 7.4029 \\
\hline 5 & 4.5 & 12.8 & 25.6 & 3.89 & 3.3134 & -11.7990 & 2.106 & 1.7528 & 6.4692 \\
\hline 6 & 4.5 & 12.8 & 51.2 & 2.28 & 2.7630 & -7.1587 & 1.987 & 1.0462 & 5.9640 \\
\hline 7 & 4.5 & 25.6 & 12.8 & 3.12 & 3.8766 & -9.8831 & 3.675 & 3.5525 & 11.3051 \\
\hline 8 & 4.5 & 25.6 & 25.6 & 4.62 & 4.3221 & -13.2928 & 2.975 & 3.1992 & 9.4697 \\
\hline 9 & 4.5 & 25.6 & 51.2 & 3.67 & 3.3360 & -11.2933 & 2.022 & 2.4926 & 6.1156 \\
\hline 10 & 9.0 & 6.0 & 12.8 & 4.37 & 4.3650 & -12.8096 & 2.789 & 3.0837 & 8.9090 \\
\hline 11 & 9.0 & 6.0 & 25.6 & 3.94 & 3.4862 & -11.9099 & 1.778 & 2.3254 & 4.9986 \\
\hline 12 & 9.0 & 6.0 & 51.2 & 2.47 & 2.9358 & -7.8539 & 1.142 & 1.8850 & 1.1533 \\
\hline 13 & 9.0 & 12.8 & 12.8 & 2.58 & 2.8659 & -8.2324 & 3.345 & 3.8521 & 10.4879 \\
\hline 14 & 9.0 & 12.8 & 25.6 & 3.65 & 3.6392 & -11.2459 & 2.250 & 2.9861 & 7.0437 \\
\hline 15 & 9.0 & 12.8 & 51.2 & 3.07 & 3.0888 & -9.7428 & 2.221 & 2.7923 & 6.9310 \\
\hline 16 & 9.0 & 25.6 & 12.8 & 3.43 & 3.5542 & -10.7059 & 5.879 & 5.2985 & 15.3861 \\
\hline 17 & 9.0 & 25.6 & 25.6 & 5.87 & 5.5986 & -15.3728 & 4.987 & 4.9452 & 13.9568 \\
\hline 18 & 9.0 & 25.6 & 51.2 & 3.33 & 3.3768 & -10.4489 & 4.107 & 4.2387 & 12.2705 \\
\hline 19 & 14.0 & 6.0 & 12.8 & 6.33 & 6.0123 & -16.0281 & 4.565 & 5.0237 & 13.1888 \\
\hline 20 & 14.0 & 6.0 & 25.6 & 3.52 & 3.8482 & -10.9309 & 6.680 & 5.983 & 16.4955 \\
\hline 21 & 14.0 & 6.0 & 51.2 & 3.44 & 3.2978 & -10.7312 & 3.486 & 3.9639 & 10.8465 \\
\hline 22 & 14.0 & 12.8 & 12.8 & 4.23 & 4.2764 & -12.5268 & 6.333 & 5.7921 & 16.0322 \\
\hline 23 & 14.0 & 12.8 & 25.6 & 3.24 & 4.0012 & -10.2109 & 5.321 & 5.4388 & 14.5199 \\
\hline 24 & 14.0 & 12.8 & 51.2 & 3.22 & 3.4508 & -10.1571 & 4.935 & 4.7323 & 13.8657 \\
\hline 25 & 14.0 & 25.6 & 12.8 & 3.75 & 4.4587 & -11.4806 & 7.332 & 7.2385 & 17.3044 \\
\hline 26 & 14.0 & 25.6 & 25.6 & 4.10 & 4.2892 & -12.2557 & 6.890 & 6.8852 & 16.7644 \\
\hline 27 & 14.0 & 25.6 & 51.2 & 3.64 & 3.7388 & -11.2220 & 6.233 & 6.1787 & 15.8939 \\
\hline
\end{tabular}


The set of optimum value obtained by Genetic algorithm for both surface roughness and material removal rate. The optimum parameters for surface roughness are peak current 4.50(A),pulse on time $6.0071(\mu \mathrm{s})$, pulse off time $51.1985(\mu \mathrm{s})$ and optimum surface roughness is 2.251. The optimum parameters for material removal rate are peak current 4.50(A),pulse on time $6(\mu \mathrm{s})$, pulse off time $14.9255(\mu \mathrm{s})$ and optimum material removal rate is $7.3391\left(\mathrm{~mm}^{3} / \mathrm{min}\right)$

In this work comparison of Taguchi parametric optimization and Genetic algorithm optimization are also reported. A Genetic algorithm will give the better optimum result compared to Taguchi parametric optimization. The improvement of surface roughness and increment of material removal rate are also done in this study. Approximately $2 \%$ of improvement is shown in surface roughness and as well as material removal rate.

\subsection{Determination of Material removal rate}

An objective function to be maximized is necessary to define the standard optimization problem. In EDM machining of titanium alloy, optimization problem can be expressed as

Maximize: MRR (IP, Ton, Toff)

Within range of machining parameters:

$$
4.5 A<I P<14 A
$$

$$
\begin{gathered}
12.8 \mu s<\text { Toff }<51.2 \mu s \\
6 \mu s<\text { Ton }<25.69 \mu s
\end{gathered}
$$

MATLAB 7.4 is used to optimize the material removal rate using Genetic Algorithms. The critical parameters of the GA are the size of the population, cross over rate and mutation rate.

$$
\begin{aligned}
& \text { Population size }=50 \\
& \text { Crossover rate }=0.70 \\
& \text { Mutation rate }=0.63
\end{aligned}
$$

The Genetic Algorithm based optimization approach provides a sufficient approximation to the true optimal solution. Tables 7 and table 8 shows the extreme of optimization function with relevant machining conditions.

\section{Table.5.ANOVA results for the MRR}

\begin{tabular}{llllllll}
\hline Sou & D & SS & MS & Fc & Ft & Infere & $\%$ \\
A & 2 & 63. & 31.8 & 76 & 4. & Signif & 62.74 \\
B & 2 & 22. & 11.4 & 27 & 4. & Signif & 22.53 \\
C & 2 & 5.2 & 2.62 & 6. & 4. & Signif & 5.18 \\
AB & 4 & 2.6 & 0.65 & 1. & 3. & Insign & 2.58 \\
BC & 4 & 1.6 & 0.41 & 1. & 3. & Insign & 1.63 \\
AC & 4 & 2.1 & 0.52 & 1. & 3. & Insign & 2.08 \\
Err & 8 & 3.3 & 0.41 & & & & 3.26 \\
Tot & 26 & 101 & & & & & 100 \\
\hline
\end{tabular}

Table.6.ANOVA results for SR

\begin{tabular}{llllllll}
\hline Sou & DF & SS & MS & Fc & F & Infere & $\%$ \\
A & 2 & 2.15 & 1.07 & 3. & 4 & Insig & 9.49 \\
B & 2 & 1.97 & 0.98 & 3. & 4 & Insig & 8.69 \\
C & 2 & 4.47 & 2.23 & 8. & 4 & Signif & 20.78 \\
AB & 4 & 2.73 & 0.68 & 2. & 3 & Insig & 12.06 \\
BC & 4 & 4.71 & 1.17 & 4. & 3 & Signif & 19.73 \\
AC & 4 & 4.41 & 1.10 & 3. & 3 & Signif & 19.49 \\
Erro & 8 & 2.21 & 0.27 & & & & 9.76 \\
Tota & 26 & 22.6 & & & & & 100 \\
\hline
\end{tabular}

A-Peak current (A), B-Pulse on time ( $\mu$ s), C-Pulse off time ( $\mu \mathrm{s}), \mathrm{AB}-$ Peak current* Pulse on time, BC-Pulse on time * Pulse off time, AC- Peak current* Pulse off time, DF-degree of freedom, SS-sum of square, Fcal-F Calculated value, Ftab-F value from tab .

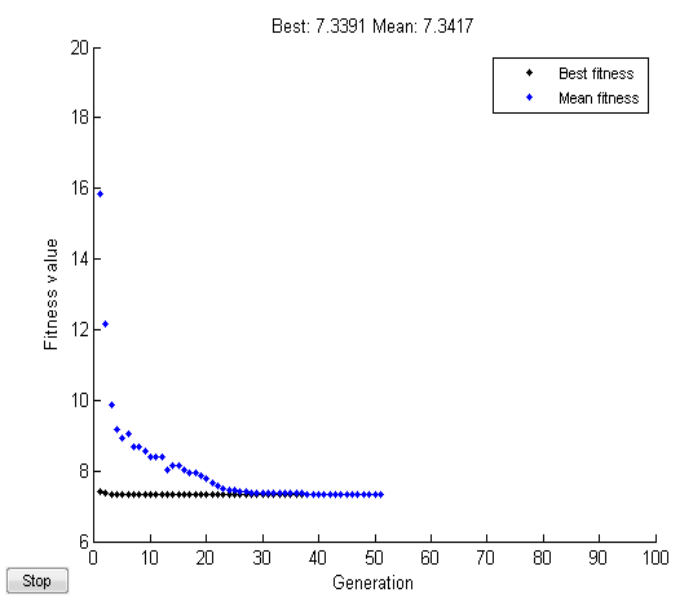

Figure .6.Genetic Algorithm fitness graph for MRR 


\section{Conformation Tests}

Since the optimal EDM process parameter set is gotten, the confirmation tests are prepared to check the performance characteristics improvement. Confirmation result is appeared in table 7 and table 8 . The experimental response variable utilizing the optimal machining parameters can be discovered for the setting not accessible in the OA.

Table 7. EDM performance results using the initial, Prediction and GA process parameters for MRR

\begin{tabular}{|l|l|l|l|l|}
\hline $\begin{array}{l}\text { Parameter/ } \\
\text { Optimized } \\
\text { Methods }\end{array}$ & $\begin{array}{l}\mathbf{A} \\
(\mathbf{A})\end{array}$ & $\begin{array}{l}\mathbf{B} \\
(\boldsymbol{\mu s})\end{array}$ & $\begin{array}{l}\mathbf{C} \\
(\boldsymbol{\mu s})\end{array}$ & $\begin{array}{l}\mathbf{M R R} \\
\mathbf{( m m}^{3} \\
/ \mathbf{m i n})\end{array}$ \\
\hline $\begin{array}{l}\text { Taguchi } \\
(\mathrm{A} 3 \mathrm{~B} 3 \mathrm{C} 1)\end{array}$ & 14 & 25.6 & 12.8 & 7.332 \\
\hline $\begin{array}{l}\text { Prdiction } \\
(\mathrm{A} 3 \mathrm{~B} 3 \mathrm{C} 1)\end{array}$ & 14 & 25.6 & 12.8 & 7.2385 \\
\hline $\begin{array}{l}\text { Genetic } \\
\text { Algorithm }\end{array}$ & 4.5 & 6 & 14.925 & 7.3391 \\
\hline $\begin{array}{l}\text { Confirmation } \\
\text { (A3B3C1) }\end{array}$ & 14 & 25.6 & 12.8 & 7.36 \\
\hline
\end{tabular}

Table 8. EDM performance results using the initial, prediction and GA process parameters for SR

\begin{tabular}{|l|l|l|l|l|}
\hline $\begin{array}{l}\text { Parameter/opt } \\
\text { imized } \\
\text { methods }\end{array}$ & $\begin{array}{l}\mathbf{A} \\
(\mathbf{A})\end{array}$ & $\begin{array}{l}\mathbf{B} \\
(\boldsymbol{\mu} \mathbf{s})\end{array}$ & $\begin{array}{l}\mathbf{C} \\
(\boldsymbol{\mu} \mathbf{s})\end{array}$ & $\begin{array}{l}\text { SR } \\
(\boldsymbol{\mu} \mathbf{m})\end{array}$ \\
\hline $\begin{array}{l}\text { Taguchi } \\
(\text { A1B2C3) }\end{array}$ & 4.5 & 12.8 & 51.2 & 2.28 \\
\hline $\begin{array}{l}\text { Prediction } \\
(\text { A1B2C3) }\end{array}$ & 4.5 & 12.8 & 51.2 & 2.763 \\
\hline $\begin{array}{l}\text { Genetic } \\
\text { Algorithm }\end{array}$ & 4.50 & 6.0071 & 51.1985 & 2.251 \\
\hline $\begin{array}{l}\text { Confirmation } \\
\text { (A1B2C3) }\end{array}$ & 4.5 & 12.8 & 51.2 & 2.27 \\
\hline
\end{tabular}

The results of confirmation experiment are compared with the outcome of the orthogonal array and regression analysis prediction of the equation operating parameters. Table 7 and table 8 shows the comparison of the experimental results using the initial (orthogonal array, A3B3C1), optimal (regression prediction, $\mathrm{A} 3 \mathrm{~B} 3 \mathrm{C} 1$ ) and Genetic algorithm EDM parameters on Ti-6Al-4V alloy. Table 7 and table 8 shows the MRR increased from 7.238 to $7.360 \mathrm{mg} / \mathrm{min}$ and the surface roughness decreased from 2.76 to $1.78 \mu \mathrm{m}$ respectively. The corresponding improvement in MRR is $2 \%$ and surface roughness $17.75 \%$, respectively.

\section{Conclusion}

Taguchi method and ANOVA analysis used to enhance the response variables of the material removal rate and surface harshness in the electrical discharge machining on $\mathrm{Ti}-6 \mathrm{Al}-4 \mathrm{~V}$ alloy was employed for in this work. Optimization of the process parameters also done in this work. The most significantly contributing factors are found by ANOVA.The experiment results shows that MRR increases with increased in the peak current and pulse on time. Surface Roughness improves by increasing pulse on time. The optimum machining conditions for material removal rate with the peak current of $14 \mathrm{~A}$, pulse on time $51.2 \mu \mathrm{s}$ and pulse off time $12.8 \mu \mathrm{s}$.In this optimum MRR is $7.332 \mathrm{mg} / \mathrm{min}$. The optimum machining conditions for surface roughness with the peak current of $4.5 \mathrm{~A}$, pulse on time $12.8 \mu \mathrm{s}$ and pulse off time $51.2 \mu \mathrm{s}$. The corresponding $\mathrm{SR}$ is $2.28 \mu \mathrm{m}$. The optimum conditions for the two response functions are different. The Genetic Algorithm will give the optimum combination of parameters for the material removal rate with peak current of $4.5 \mathrm{~A}$, pulse on time $6 \mu \mathrm{s}$ and pulse off time $14.9254 \mu \mathrm{s}$. In this optimum Material removal rate is $7.3391 \mathrm{mg} / \mathrm{min}$. The optimum combination of parameters for the surface roughness attained with the peak current of $4.50052 \mathrm{~A}$, pulse on time of $6.00718 \mu$ s and pulse off time of $51.19852 \mu \mathrm{s}$. The corresponding optimum Surface roughness is $2.2518 \mu \mathrm{m}$.

\section{References}

1. J. Y. Kao , C. C. Tsao ,S. S. Wang, C. Y. Hsu, Int J Adv Manuf Technology, vol.47, pp.395-402, 2010.

2. K. Ponappa , S. Aravindan ,P. V. Rao , J. Ramkumar, Int J Adv Manuf Technology, vol.46, pp.1035-1042, 2010 .

3. Anand Pandey,Shankar Singh, International Journal of Engineering Science and Technology ,Vol. 2(6), pp.2172-2191, 2010.

4. Velusamy Senthilkumar, Bidwai Uday Omprakash, Journal of Manufacturing Processes ,vol.13, pp.60-66, 2011.

5. C. Sharma,S. Maheshwari, Pushpendra S Bharti, International Journal of Engineering Science and Technology, Vol. 2(11), pp.6464-6473, 2010.

6. Yan-Cherng Lin ,Yuan-Feng Chena, Der-An Wanga, Ho-Shiun Lee, Journal of materials processing technology, vol.209, pp.3374-3383, 2009.

7. S.N. Joshi, S.S. Pande, Int.J. Adv. Manufact. Technology, vol.45 (3), 2009. 
8. P. Narender Singh, K. Raghukandan, B.C. Pai, Journal of Materials Processing Technology, vol.155156, pp.1658-1661, 2004.

9. P.M. George a, B.K. Raghunath , L.M. Manochac, Ashish M. Warrier, Journal of Materials Processing Technology, vol.145, pp.66-71, 2004. 10. Sooriya moorthy Elangovan, K. Prakasan, V. Jaiganesh, Int J Adv Manuf Technology,vol.51, pp.163$171,2010$.

11. G. Akhyar,C.H. Che Haron, J.A. Ghani, International Journal of Science Engineering and Technology, Vol. 1, pp.1985-3785, 2008.
12. G.Krishna Mohan araoa, G.Rangajanardhaa, D.Hanumantha Raoc, Journal of materials processing technology, vol.209, pp.1512-1520, 2009.

13. G.Anand, S.Satyanarayana and M.Manzoor Hussain, International Journal of materials today, Vol.4, pp.7723-7730, 2017.

14. S.Chandramouli and K.Eswaraiah, International Journal of materials today, Vol.4, pp. 2040-2047, 2017.

15. Ross PJ "Taguchi techniques for quality engineering”, Tata McGraw-Hill, New Delhi, 2005. 